\title{
COMPORTAMENTO DE SEMENTES DE MILHO HÍBRIDO DURANTE O ARMAZENAMENTO SOB CONDIÇÕES VARIÁVEIS DE TEMPERATURA E UMIDADE RELATIVA DO AR
}

\author{
D.A.C. BILIA; A.L. FANCELLI; J. MARCOS FILHO \\ Departamento de Agricultura - ESALQ/USP, C.P. 9, CEP: 13418-900 - Piracicaba,SP. \\ J.A. MACHADO \\ ZENECA, Via Anhanguera, km. 296 - CEP: $14140-000$ - Cravinhos,SP
}

\begin{abstract}
RESUMO: Com o objetivo de avaliar o comportamento de sementes de milho hibrido durante o armazenamento sob condiçōes diversas de temperatura e umidade relativa do ar foram utilizadas sementes do híbrido Pioneer 3072 e 3210, as quais foram armazenadas sob três condições distintas: câmara seca, câmara fria e condição ambiente, durante 6 meses, e avaliadas quanto à qualidade fisiologica em 3 épocas bimestrais distintas, sendo parte submetida à estresse adicional no momento de realização dos testes. Para deteç̧ão da diferença de comportamento dos materiais estudados foram empregados os testes de germinação, primeira contagem de germinação, envelhecimento acelerado, frio (com ou sem solo), condutividade elétrica e emergência de plântulas em campo. Póde-se concluir que: o controle da temperatura e umidade relativa do ar do ambiente de armazenamento, principalmente da umidade relativa do ar (câmara seca), favorece a conservação da qualidade das sementes.

Descritores: sementes, milho, armazenamento
\end{abstract}

\section{BEHAVIOUR OF HYBRID CORN SEEDS DURING STORAGE UNDER DIFFERENT CONDITIONS OF AIR TEMIPERATURE AND RELATTVE HUMIDITY}

\begin{abstract}
To evaluate the performance of early and normal hybrid corn seeds during storage under different conditions of temperature and relative humidity, Pioneer 3072 and 3210 hybrid seeds were stored under three different conditions, for sixth months. Evaluations of the physiological quality of the seeds were carried out in three bimonthly periods, part of the seeds having been submitted to additional stress at the time tests were conducted. The performance differences between the studied treatments were achieved through the employment of tests of germination, first count, accelerated aging, cold (with and without soil), electrical conductivity and seedling field emergence. It is concluded that: the control of temperature and relative humidity of the storage ambient, mainly relative humidity (dry chamber), favour the conservation of the hybrid corn seed quality.
\end{abstract}

Key Words: Corn, seeds, storage.

\section{INTRODUÇÃO}

A utilização de sementes de boa qualidade na instalação de lavouras de milho é fundamental para o estabelecimento da cultura no campo.

A deterioração das sementes se constitui em grande problema para a agricultura, sendo responsável por sériàs perdas no mundo inteiro $\mathbf{e}$, principalmente, nos trópicos onde, de maneira geral, elevadas temperaturas e umidades relativas do ar prevalecem durante a maturação e o armazenamento do produto.

Embora a deterioração seja irreversível e inevitável, a velocidade do processo pode, até certo ponto, ser controlada pelo emprego de técnicas adequadas de colheita, secagem, beneficiamento e armazenamento (POPINIGIS, 1977).

A umidade relativa do ar, diretamente relacionada com o conteúdo de umidade das sementes, e a temperatura no ambiente de armazenamento são os fatores ambientais que mais afetam a manutenção da qualidade durante o armazenamento (HARRINGTON, 1973; DELOUCHE et al., 1973; ROOS, 1986).

De uma maneira geral, as elevações de temperatura e de umidade relativa do ar correspondem a elevações das perdas qualitativas no produto armazenado. Estas perdas, relacionadas diretamente com as decorrências metabólicas que as 
alterações no ambiente podem promover, têm, ainda, ligações com os estímulos proporcionados à atividade de bactérias, fungos e insetos associados às sementes (BOSSER, 1982).

Face ao exposto, o presente trabalho visou verificar o comportamento de sementes de milho, durante o armazenamento, sob condições diversas de temperatura e umidade relativa do ar.

\section{MATERIAL E MÉTODOS}

O presente estudo foi conduzido no laboratório de análise de sementes e no campo experimental do Departamento de Agricultura da ESALQ/USP, em Piracicaba-SP.

Amostras de sementes de milho da empresa Pioneer, cultivares P3072 (híbrido simples, superprecoce) e P3210 (híbrido triplo de ciclo normal), tratadas com CAPTAN, K-OBIOL E ACTELIC, foram homogeneizadas, divididas, acondicionadas em sacos de papel "kraft" e armazenadas em condições distintas, a saber:

- Câmara fria: $\left(10^{\circ} \mathrm{C}\right.$ e $90 \%$ UR)

- Câmara seca: $\left(22^{\circ} \mathrm{C}\right.$ e $35-45 \%$ UR)

- Condição ambiente: $\left(17-24^{\circ} \mathrm{C}\right.$ e $64-83 \%$ UR)

Após a caracterização inicial da qualidade, as sementes permaneceram armazenadas por 6 meses: durante esse período, foram realizadas avaliações bimestrais, sendo que, no momento dos testes, uma parte das sementes foi submetida à estresse, permanecendo por 24 horas a $42^{\circ} \mathrm{C} \mathrm{em} \mathrm{reci-}$ piente hermético, tipo gerbox, com água disponível para proporcionar $100 \%$ UR em seu interior.

Todos os tratamentos foram submetidos aos seguintes testes para a avaliação da qualidade fisiológica:

- Teste de germinação (TG): realizado de acordo com as Regras para Análise de Sementes (BRASIL, 1980 ), empregando temperatura de $30^{\circ} \mathrm{C}$.

- Teste de primeira contagem de germinação (PCG): conduzido conjuntamente com o teste padrão de germinação, de acordo com as Regras para Análise de Sementes (BRASIL, 1980).

- Teste de envelhecimento acelerado (EA): executado de acordo com metodologia descrita por POPINIGIS (1977).

- Teste de frio com utilização de solo (TFS): realizado de acordo com FRATIN (1987).
- Teste de frio sem solo (TF): executado de acordo com FRATIN (1987).

- Teste de condutividade elétrica (CE): efetuado de acordo com FRATIN (1987), com escolha de sementes sob lupa.

- Emergência de plântulas em campo (EM): realizado com 4 repetições, sendo cada parcela constituída por uma linha de 4 metros de comprimento, onde foram distribuídas 100 sementes com espaçamento entre sulcos de $0,40 \mathrm{~m}$, com $0,07 \mathrm{~m}$ de profundidade, sendo as sementes cobertas com $0,02 \mathrm{~m}$ de solo. A contagem do número de plantas emersas foi efetuada 15 dias após a semeadura. Os dados observados nos diferentes testes, exceto os do teste de condutividade elétrica, sofreram transformação em arc sen $(x / 100)$ para análise de variância.

A análise estatística foi efetuada, adotando o delineamento experimental inteiramente casualizado em parcelas subdivididas, com 12 tratamentos e 4 repetições, com o auxílio do Programa de Sistema de Análise Estatística (ZONTA et al. 1984). A comparação entre as médias foi realizada empregando o Teste de Tukey, em nível de $5 \%$ de probabilidade.

\section{RESULTADOS E DISCUSSÃo}

A TABELA 1 apresenta os resultados médios obtidos nos testes de avaliação da qualidade fisiológica de sementes de milho hibrido, armazenadas em três ambientes diversos, em função de cada época de avaliação. Salienta-se que, nesse caso, os híbridos e os estresses foram considerados como fator único de causa de variação. De modo geral, aos 2 meses de armazenamento, não foi possível observar um comportamento distinto entre as sementes provenientes dos diferentes ambientes de armazenamento. Já, aos 4 meses de armazenamento, a câmara fria e a seca possibilitaram uma conservação superior da qualidade das sementes armazenadas, que mostraram um melhor desempenho nos testes de frio com e sem a utilização do solo. Esse mesmo comportamento foi verificado no teste de envelhecimento acelerado na avaliação realizada aos 6 meses de armazenamento, com redução considerável da média. Ainda, na avaliação aos 6 meses, foi possível observar que as diferenças entre os ambientes, quanto à eficácia de conservação da qualidade das sementes, se acentuaram com maior eficiência da câmara seca, seguida da câmara fria e da condição ambiente. 
TABELA 1 - Valores médios obtidos na avaliação da qualidade fisiológica das sementes de milho híbrido armazenados em diferentes condições de armazenamento: câmara seca (CS), câmara fria (CF) e condição ambiente (CA), em função de cada época de avaliação.

\begin{tabular}{|c|c|c|c|c|c|c|c|c|}
\hline \multirow[t]{2}{*}{ Epocas } & \multirow[t]{2}{*}{ Ambientes } & \multicolumn{7}{|c|}{ Testes } \\
\hline & & $\begin{array}{l}\text { TG } \\
(\%) \\
\end{array}$ & $\begin{array}{c}\text { PCG } \\
(\%) \\
\end{array}$ & $\begin{array}{l}\mathrm{EM} \\
(\%) \\
\end{array}$ & $\begin{array}{l}\text { EA } \\
(\%) \\
\end{array}$ & $\begin{array}{l}\text { TFS } \\
(\%) \\
\end{array}$ & $\begin{array}{r}\text { TF } \\
(\%) \\
\end{array}$ & $\begin{array}{c}\mathrm{CE} \\
(\mu \mathrm{mhos} / \mathrm{g}) \\
\end{array}$ \\
\hline \multirow{3}{*}{2 meses } & Cs & $98 a_{Q}$ & $94 b$ & $96 a$ & $96 a$ & $96 \mathrm{a}$ & $94 a$ & $11,17 \mathrm{~b}$ \\
\hline & $\mathrm{CF}$ & $97 \mathrm{a}$ & $96 a$ & $94 a$ & $91 \mathrm{c}$ & $96 a$ & $94 a$ & $10,27 \mathrm{a}$ \\
\hline & $\mathrm{CA}$ & $97 \mathrm{a}$ & $93 b$ & $94 a$ & $93 \mathrm{~b}$ & $93 a$ & $92 b$ & $10,27 \mathrm{a}$ \\
\hline \multirow[t]{2}{*}{ CV (\%) } & & 4,86 & 3,66 & 4,53 & 4,45 & 2,47 & 2,76 & 7,51 \\
\hline & $\mathrm{CS}$ & $97 \mathrm{a}$ & $92 a$ & $96 a$ & $93 a$ & $94 a$ & $94 a$ & $11,76 a$ \\
\hline \multirow[t]{2}{*}{4 meses } & CF & $97 \mathrm{a}$ & $92 a$ & $94 a$ & $93 a$ & $94 a$ & $93 a$ & $11,07 a$ \\
\hline & $\mathrm{CA}$ & $96 a$ & $92 a$ & $96 \mathrm{a}$ & $93 a$ & $87 \mathrm{~b}$ & $90 \mathrm{~b}$ & $11,09 \mathrm{a}$ \\
\hline \multirow[t]{2}{*}{ CV (\%) } & & 2,95 & 4,29 & 6,02 & 3,46 & 3,43 & 3,30 & 7,04 \\
\hline & $\mathrm{CS}$ & $96 a$ & $93 a$ & $94 a$ & $92 \mathrm{a}$ & $95 a$ & $95 a$ & $11,29 a$ \\
\hline \multirow[t]{2}{*}{6 meses } & $\mathrm{CF}$ & $96 a$ & $90 a$ & $95 \mathrm{a}$ & $91 \mathrm{a}$ & $88 b$ & $92 b$ & $10,95 a$ \\
\hline & CA & $95 a$ & $91 \mathrm{a}$ & $93 a$ & $80 a$ & $80 c$ & $88 c$ & $12,11 \mathrm{a}$ \\
\hline CV (\%) & & 4,20 & 4,29 & 4,94 & 5,58 & 3,38 & 3,14 & 8,10 \\
\hline
\end{tabular}

Na mesma coluna, médias seguidas pela mesma letra não diferiram entre si, pelo teste de Tukey, ao nível de $5 \%$ de probabilidade.

Na TABELA 2 são apresentados os valores médios obtidos na avaliação da qualidade fisiológica de sementes de milho híbrido, armazenados em três ambientes diversos, em função das três épocas bimestrais distintas. Os dados obtidos no transcorrer do armazenamento confirmam a tendência observada dentro de cada Época, mostrando a superioridade da câmara seca sobre a câmara fria $e$, desta, sobre a condição ambiente, verificada nos testes e envelhecimento acelerado, e testes de frio com e sem a utilização de solo.

Pelo que se observou, entre os testes utilizados para a avaliação da qualidade fisiológica das sementes, os mais sensíveis na detecção de diferenças de vigor foram os testes de envelhecimento acelerado e os testes de frio com e sem solo, resultados esses que vêm ratificar sua importância, pois são considerados como alguns dos mais indicados simultaneamente pela INTERNATIONAL SEED TESTING ASSOCIATION (1981) e pela ASSOCIATION OF OFFICIAL SEED ANALYSIS (1983), de acordo com CARVALHO (1986).

Deste modo fica claro a menor eficácia de conservação da qualidade proporcionada pela condição ambiente e a superioridade da cámara seca sobre a câmara fria em função do prolongamento do período de armazenamento.

Com base nas pesquisas já realizadas é possível afirmar que as condições de temperatura e umidade relativa do ar, nas condições de ambiente, constituem-se em fatores preponderantes para a plena conservação da sementes durante o armazenamento. 
TABELA 2 - Valores médios obtidos na avaliação da qualidade fisiológica das sementes de milho hibrido armazenados em diferentes condições de armazenamento: câmara seca (CS), câmara fria (CF) e condição ambiente (CA), em função de três épocas bimestrais de avaliação.

\begin{tabular}{cccccccc}
\hline \hline \multirow{2}{*}{ Ambientes } & \multicolumn{7}{c}{ Testes } \\
\cline { 2 - 8 } & TG & PCG & EM & EA & TFS & TF & CE \\
& $(\%)$ & $(\%)$ & $(\%)$ & $(\%)$ & $(\%)$ & $(\%)$ & $(\mu \mathrm{mhos} / \mathrm{g})$ \\
\hline CS & $98 \mathrm{a}$ & $93 \mathrm{a}$ & $95 \mathrm{a}$ & $94 \mathrm{a}$ & $95 \mathrm{a}$ & $94 \mathrm{a}$ & $11,40 \mathrm{~b}$ \\
CF & $97 \mathrm{ab}$ & $93 \mathrm{a}$ & $95 \mathrm{a}$ & $92 \mathrm{~b}$ & $93 \mathrm{~b}$ & $93 \mathrm{~b}$ & $10,47 \mathrm{a}$ \\
$\mathrm{CA}$ & $97 \mathrm{~b}$ & $92 \mathrm{a}$ & $94 \mathrm{a}$ & $89 \mathrm{c}$ & $88 \mathrm{c}$ & $90 \mathrm{c}$ & $11,46 \mathrm{ab}$ \\
\hline CV $(\%)$ & 4,09 & 4,08 & 5,21 & 4,54 & 3,09 & 3,07 & 7,57 \\
\hline \hline
\end{tabular}

Na mesma coluna, médias seguidas pela mesma letra não diferiram entre si, pelo teste de Tukey, ao nível de $5 \%$ de probabilidade.

Assim, quando as mesmas não se encontrarem dentro do limite correspondente a (TC $+\% U<80$ ), conforme apontado por DELOUCHE et al. (1973), para o armazenamento durante 9 meses, acarretarão nível significativo de deterioração natural. Os resultados obtidos pelo presente trabalho, confirmam e reforçam a recomendação de condições controladas para a preservação da qualidade das sementes.

Também de acordo com PEREIRA (1992), o armazenamento de grãos requer cuidados especiais sob condições de umidade relativa do ar superior a 70\%. Neste caso, uma porção considerável de água contida no grão se dispersa nos constituintes coloidais e, eventualmente, pode preeencher os espaços capilares entre partículas constituintes dos grãos. Desta forma uma quantidade de água se torna disponivel e pode ser utilizada para reações químicas e bioquímicas, tais como as reações enzimáticas e a desnaturação de proteínas.

\section{CONCLUSÃO}

O controle da temperatura e umidade relativa do ar do ambiente de armazenamento, principalmente da umidade relativa do ar (câmara seca), favorecem a conservação da qualidade das sementes de milho hibrido.

\section{REFERENCIAS BIBLIOGRÁFICAS}

ASSOCIATION OF OFFICIAL SEED ANALYSTS.

Seed vigor testing handbook. Springfield, 1983. 88p. (Contribution, 32).

BOSSER, F. Conservação dos cereais e outros produtos granulados por meio de resfriamento. In: SEMINÁRIO NACIONAL DE ARMAZENAGEM, 3., 1978. Curitiba, Anais... Curitiba: Companhia Paranaense de Silos e Armazéns, 1982. p.48-54.

BRASIL, Ministério da Agricultura. Secretaria Nacional de Defesa Agropecuária. Regras para analise de semente. Brasilia, 1980, 188p.

CARVALHO, N.M. Vigor de sementes. In: CfCERO, S.M.; MARCOS FILHO, J.; SILVA, W.R., (Coord.). Atualização em produção de sementes. Campinas: Fundação Cargill, 1986. p.207-223.

DELOUCHE, J.C.; MATTHES, K.K.; DOUGHERTY, G.M.; BOYD, A.H. Storage of seed in sub-tropical and tropical regions. Seed Science and Technology, Zurich, v.1, n.3, p.671-700, 1973. 
FRATIN, P. Comparação entre métodos para a avaliaçũo da qualidade fisiológica de sementes de milho (Zea mays L.). Piracicaba, 1987. 191p. Dissertação (Mestrado) - Escola Superior de Agricultura "Luiz de Queiroz", Universidade de São Paulo.

HARRINGTON, J.F. Problems of seed storage. In: HEYDECKER, W.H., (Ed.). Seed ecology. Nottingham: Pennsylvania State University Press, 1973. cap.14, p.251-265.

INTERNATIONAL SEED TESTING ASSOCIATION. Handbook of vigour test methods. Zurich, 1981. $1172 p$.

PEREIRA, J.A.M. Água no grão. In: CURSO DE ARMAZENAMENTO DE SEMENTES, 1992, Viçosa, CENTREINAR, 1992. Resumos... p.irreg.
POPINIGIS, F. Fisiologia da semente. Brasília: Ministério da Agricultura/AGIPLAN, 1977. 289p.

ROOS, E.E. Precepts of successfull seed storage. In: MCDONALD JÚNIOR, M.B.; NELSON, C.J., (Ed.). Physiology of seed deterioration. Madison: CSSA, 1986. cap.1, p.1-25. (CSSA Publication, 11).

ZONTA, E.P.; MACHADO, A.A.; SILVEIRA JÚNIOR, P. Sistema de analise estatística para microcomputadores - SANEST. Pelotas, UFPel, 1984. 88p.

Enviado para publicação em 06.04 .93

Aceito para publicação em 21.09 .93 